\title{
Beta cell differentiation during early human pancreas development
}

\author{
K Piper ${ }^{1}$, S Brickwood ${ }^{1}$, L W Turnpenny ${ }^{1}$, I T Cameron ${ }^{2,3}$, \\ S G Ball ${ }^{4}$, D I Wilson ${ }^{1}$ and N A Hanley ${ }^{1,3}$
}

\author{
${ }^{1}$ Division of Human Genetics, University of Southampton, Southampton General Hospital, Tremona Road, Southampton SO16 6YD, UK \\ ${ }^{2}$ Maternal, Fetal and Neonatal Physiology Group, Fetal Origin of Adult Disease Division, University of Southampton, Southampton General Hospital, \\ Tremona Road, Southampton SO16 6YD, UK \\ ${ }^{3}$ Southampton Endocrinology Group, University of Southampton, Southampton General Hospital, Tremona Road, Southampton SO16 6YD, UK \\ ${ }^{4}$ School of Clinical Medical Sciences, Newcastle University, Claremont Place, Newcastle upon Tyne NE2 4HH, UK \\ (Requests for offprints should be addressed to N A Hanley, Division of Human Genetics, Duthie Building (Mailpoint 808), Southampton General Hospital, \\ Tremona Road, Southampton SO16 6YD, UK; Email: n.a.hanley@soton.ac.uk)
}

\begin{abstract}
Understanding gene expression profiles during early human pancreas development is limited by comparison to studies in rodents. In this study, from the inception of pancreatic formation, embryonic pancreatic epithelial cells, approximately half of which were proliferative, expressed nuclear PDX1 and cytoplasmic CK19. Later, in the fetal pancreas, insulin was the most abundant hormone detected during the first trimester in largely nonproliferative cells. At sequential stages of early fetal development, as the number of insulin-positive cell clusters increased, the detection of CK19 in these cells diminished. PDX1 remained expressed in fetal beta cells. Vascular structures were present within the loose stroma surrounding pancreatic epithelial cells during embryogenesis. At
\end{abstract}

10 weeks post-conception (w.p.c.), all clusters containing more than ten insulin-positive cells had developed an intimate relationship with these vessels, compared with the remainder of the developing pancreas. At 12-13 w.p.c., human fetal islets, penetrated by vasculature, contained cells independently immunoreactive for insulin, glucagon, somatostatin and pancreatic polypeptide (PP), coincident with the expression of maturity markers prohormone convertase $1 / 3(\mathrm{PC} 1 / 3)$, islet amyloid polypeptide, Chromogranin A and, more weakly, GLUT2. These data support the function of fetal beta cells as true endocrine cells by the end of the first trimester of human pregnancy. Journal of Endocrinology (2004) 181, 11-23

\section{Introduction}

Informative studies of human pancreas development have been restricted in number by ethical constraints and access to tissue, particularly during the first trimester, placing understandable reliance on data from the use of mice and other species (e.g. rat, frog and chick). Such data have highlighted a critical role for the pancreas-duodenum homeobox 1 gene $(P d x 1$, also known as insulin promoter factor 1) (Edlund 2002), targeted disruption of which causes pancreatic regression soon after bud formation (Jonsson et al. 1994, Offield et al. 1996). Similarly, homozygous and heterozygous loss-of-function mutation of PDX1 in humans has been associated with pancreatic agenesis and maturity onset diabetes of the young (MODY) respectively, suggesting a clear role for the transcription factor during human development (Stoffers et al. 1997a,b). Despite these data, we have no direct knowledge of PDX1 expression during human pancreas formation. These data are relevant as subtle differences between human and mouse development have been described for other key regulatory genes (e.g. SRY
(Hanley et al. 2000), SOX9 (Hanley et al. 2000) and WNT7 (Fougerousse et al. 2000)). Detailed morphological assessment of embryogenesis has also revealed unexpected differences between vertebrates (including mouse and human) (Richardson et al. 1997) and human development ceases to be a linear correlate of the rodent process during the second and third trimester of pregnancy. As evidence of the latter divergence, islets form relatively early during human gestation. However, it is less clear when endocrine cells become vascularised and express markers of mature function (e.g. expression of prohormone convertase 1/3 $(\mathrm{PC} 1 / 3))$. Taken together, these findings advise direct study, wherever possible, of human beta cell formation directly in human tissue, if only to corroborate the corresponding wealth of data from other species (reviewed in Slack 1995, Sander \& German 1997 and Kim \& Hebrok 2001).

To address these questions, in this immunohistochemical study we describe beta cell differentiation in precisely staged human embryonic and early fetal material, correlated to cell proliferation, vascular development and the expression of markers of mature islet cell function. 
Table 1 Primary antibodies

\begin{tabular}{|c|c|c|c|}
\hline & Raised in: & Dilution & Source \\
\hline \multicolumn{4}{|l|}{ Primary antibody } \\
\hline Polyclonal anti-insulin & Guinea-pig & $1: 50$ & Zymed Laboratories, San Francisco, CA, USA \\
\hline Polyclonal anti-glucagon & Rabbit & $1: 50$ & Zymed Laboratories \\
\hline Polyclonal anti-somatostatin & Rabbit & $1: 50$ & Zymed Laboratories \\
\hline Monoclonal anti-somatostatin & Rat & $1: 200$ & Chemicon International Inc., Temecula, CA, USA \\
\hline Polyclonal anti-PP & Rabbit & $1: 50$ & Zymed Laboratories \\
\hline Polyclonal anti-IAPP & Rabbit & $1: 300$ & Peninsula Laboratories, San Carlos, CA, USA \\
\hline Polyclonal anti-GLUT2 & Rabbit & $1: 800$ & Chemicon International Inc. \\
\hline Monoclonal anti-Chromogranin A & Mouse & $1: 250$ & Chemicon International Inc. \\
\hline Monoclonal anti-CD34 & Mouse & $1: 50$ & Novocastra Ltd, Newcastle-upon-Tyne, UK \\
\hline Monoclonal anti-CK19 & Mouse & $1: 100$ & Novocastra Ltd \\
\hline Monoclonal anti-Ki67 & Mouse & $1: 200$ & Novocastra Ltd \\
\hline
\end{tabular}

These data are coupled with the expression profile of PDX1 and discussed in relation to previous research on the human pancreas during early development.

\section{Materials and Methods}

\section{Carnegie staging of human embryos and fetal staging}

The collection and use of human embryonic and fetal material was carried out following ethical approval from the Southampton \& South West Hampshire Local Research Ethics Committee and Newcastle Health Authority, under guidelines issued by the Polkinghorne committee. Human embryos were collected with informed consent following medical (mifepristone and prostaglandin) or surgical termination of pregnancy and staged immediately by stereomicroscopy according to the Carnegie classification (O'Rahilly \& Müller 1987, Bullen \& Wilson 1997). Fetal material was also obtained following second trimester termination and hand and foot length measured to give a direct estimate of fetal age (as weeks post-conception (w.p.c.)). All specimens were promptly and identically fixed in 4\% paraformaldehyde (PFA) for embedding in paraffin wax. This included control mouse tissue, which was processed in parallel using an identical method. The reproduction of published murine data was designed to validate the results obtained for PDX1 upon human material. To ensure that results were representative and unchanged by choice of fixative, further human fetal control tissue was processed in an alternative methanol:acetic acid fixative. Embedded tissue was sectioned at $5 \mu \mathrm{m}$ thickness.

\section{Immunohistochemistry}

Optimal conditions were determined for each antibody by testing the use of several blocking and antigen-unmasking techniques. Previously, all 16 fetal pancreatic specimens used in this study had demonstrated positive immunoreactivity to a range of antibodies indicating satisfactory tissue preparation. Identical conditions were used for the human sections and the control mouse material. By this approach, the same PDX1 antibody mix was exposed to both human and mouse tissues at the same time, based on the technique of the laboratory providing the antibody (gift of Dr Chris Wright, Vanderbilt University, Nashville, TN, USA). Slides were dewaxed, rehydrated and washed in phosphate-buffered saline (PBS). For the use of biotinylated secondary antibodies, sections were pretreated with 3\% (v/v) hydrogen peroxide in PBS to quench endogenous peroxidase prior to antigen retrieval by boiling in $10 \mathrm{mM}$ sodium citrate (Ki67, CK19 and PDX1) or incubation at room temperature in 1\% trypsin (all other antibodies) for stage-dependent times. Incubation with primary antibody was overnight at $4{ }^{\circ} \mathrm{C}$ (Table 1$)$. Sections were washed in PBS and incubated with either biotin- or fluorescently-labelled secondary antibodies for $2 \mathrm{~h}$ at $4{ }^{\circ} \mathrm{C}$ or subject to the Vector Red alkaline phosphatase protocol according to the manufacturer's instructions (Vector Laboratories, Burlingame, CA, USA). Anti-guinea pig (1:200 dilution), anti-rabbit (1:800), anti-goat (1:300) and anti-mouse $(1: 100)$ biotinylated or alkaline phosphatase-labelled antibodies were used (all from Vector Laboratories). Fluorescently labelled secondary antibodies were Texas Red anti-guinea pig or anti-rabbit (both 1:150; Vector Laboratories) and FITC anti-mouse (1:64; Sigma Chemical Co., St Louis, MO, USA). For biotinylated secondary antibodies, further washing was followed by incubation for $1 \mathrm{~h}$ at room temperature with streptavidin (SA) horseradish peroxidase (1:200; Vector Laboratories) or SA-FITC (1:150; Sigma Chemical Co.) conjugates. All antibodies used have been validated commercially with the exception of anti-PDX1 (Peshavaria et al. 1994), extensively used by many researchers. Controls for all experiments included the omission of 

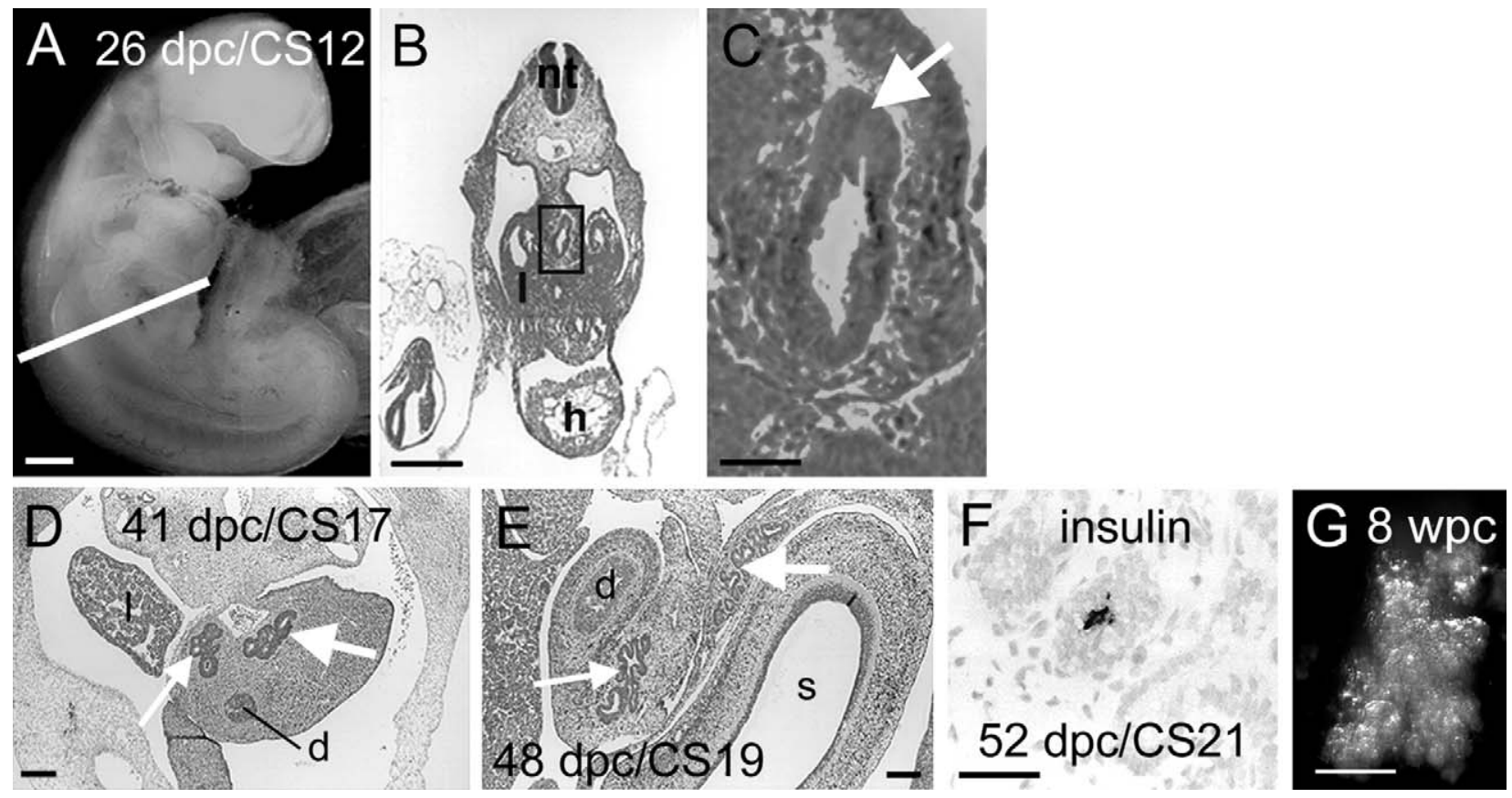

Figure 1 Human pancreas formation and early insulin biosynthesis. (A) Human embryo at 26 d.p.c./CS12. The white line indicates the plane of transverse section shown in (B). (B-F) Transverse sections of human embryos at 26 d.p.c./CS12 (B-C), 41 d.p.c./CS17 (D), 48 d.p.c./CS19 (E) and 52 d.p.c./CS21 (F) stained with H \& E (B-E) and toluidine blue (F). (B) Outgrowth of dorsal pancreatic bud from the embryonic duodenum is boxed and enlarged in (C). (C)-(E) Positions of the dorsal and ventral pancreatic buds are marked with large and small arrows respectively. (F) Immunohistochemical staining of insulin. (G) Epithelial clusters, visible as aggregates of cells during pancreatic dissection by stereomicroscopy. d, duodenum; h, heart; I, liver; nt, neural tube; s, stomach. Size bars represent 500 (A, B) and $125 \mu \mathrm{m}(\mathrm{C}-\mathrm{G})$.

primary or secondary antibody. For bright-field immunohistochemistry, the colour reaction was developed with diaminobenzidine containing $0 \cdot 1 \%$ hydrogen peroxidase for $3 \mathrm{~min}$. Sections were counter-stained with toluidine blue. Dual immunofluorescence labelling was carried out sequentially. Slides for morphological analysis were stained with haematoxylin and eosin $(\mathrm{H} \& \mathrm{E})$. Image analysis utilised a Zeiss Axiovert/Axiovision imaging system. Cell counting was carried out by two observers, blinded to the study.

\section{Results}

\section{General morphology}

The human pancreas develops as ventral and dorsal outgrowths of foregut endoderm. Using the Carnegie staging (CS) system, the dorsal derivative was first visible at 26 days post-conception (d.p.c.), which is CS12 (Fig. 1A-C). During embryogenesis, these buds extended into the surrounding mesenchyme, the ventral portion rotating to the right of and then behind the developing duodenal loop (Fig. 1D, E). In this location, it was apposed to the dorsal primordium, with which it fused at the end of the embryonic period (56 d.p.c.). During this period, the epithelial cells of the pancreas were arranged as simple tubular structures within a loose mesenchymal stroma. In contrast, during the early fetal period, more branched epithelial clusters were apparent, visible as aggregates of cells during pancreatic dissection by stereomicroscopy (Fig. 1G).

\section{Hormone expression}

Hormone expression, evident as rare epithelial cells immunoreactive for insulin, was first apparent at 52 d.p.c./CS21, almost 4 weeks after the initial outgrowth of the human pancreatic buds (Fig. 1F). Glucagon, somatostatin and pancreatic polypeptide (PP) were not detected at this stage in several specimens. One week later (immediately after the embryonic period) at 8.5 w.p.c., glucagon and somatostatin were expressed separately in isolated epithelial cells (arrows, Fig. 2A), with a relative prevalence of insulin $>>$ glucagon $>$ somatostatin (Table 2). Insulin-positive cells were more distinct as cell clusters up to about five cells in diameter and $\sim 13$-fold more numerous than those expressing glucagon (Fig. 2A, Table 2). The number of hormone-expressing cells was increased at 10 w.p.c., by which time PP was also detected (Fig. 2B, Table 2). Insulin-positive cells, in clusters of up 


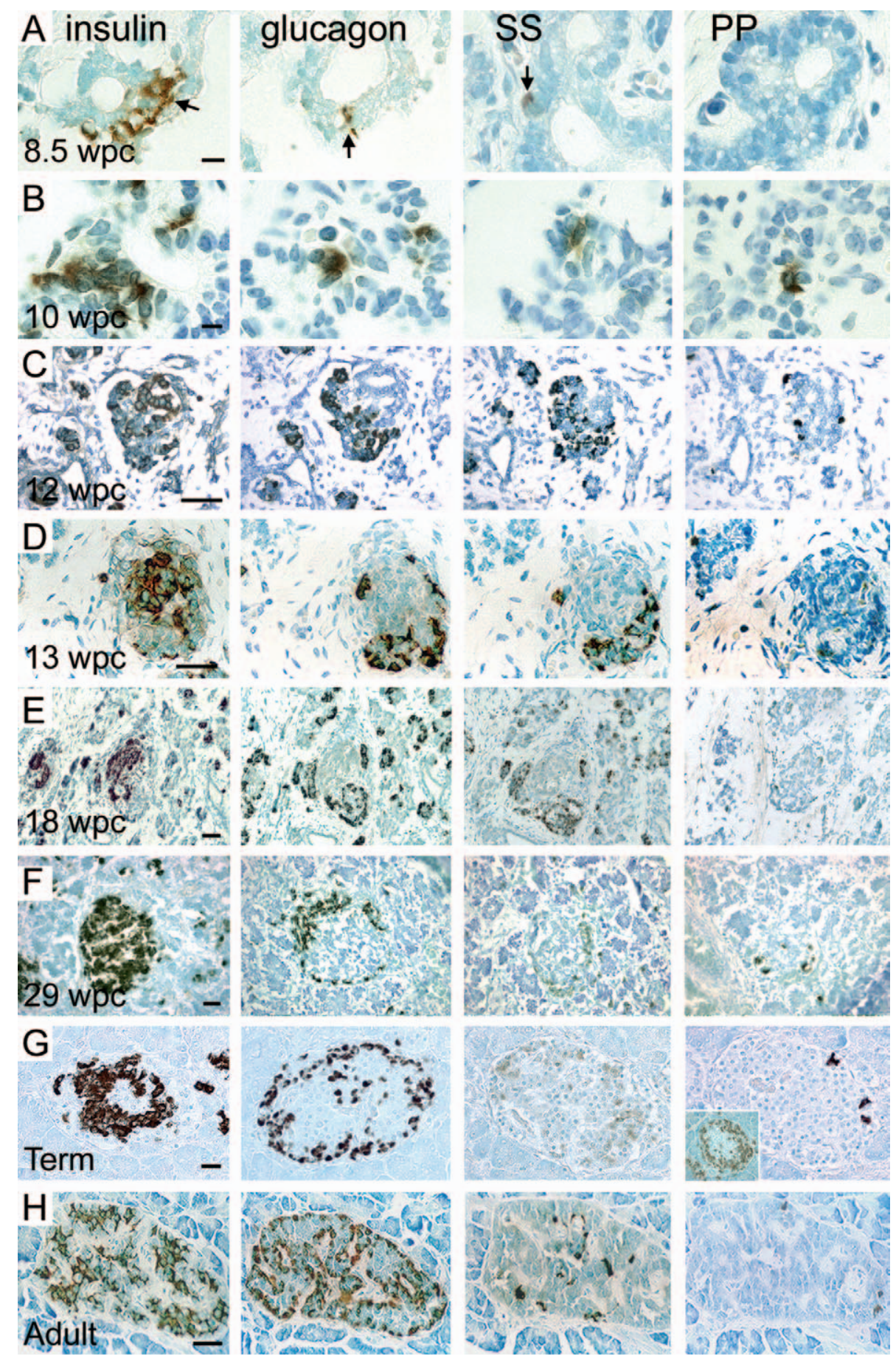

Figure 2 Hormone biosynthesis within the developing human pancreas. Bright-field images of transverse sections of human dorsal pancreas from 8.5 w.p.c. to adult counter-stained with toluidine blue. At each time point, immunohistochemistry panels are shown for insulin, glucagon, somatostatin (SS) and PP. In (A) and (B) different areas of serial sections are shown to permit the demonstration of immunoreactivity. For $(\mathrm{C})-(\mathrm{H})$ serial $5 \mu \mathrm{m}$ sections of the same islet are shown. Arrows in (A) illustrate immunoreactive cells for each hormone. The inset in (G) demonstrates PP immunoreactivity in ventral pancreatic derivative from same specimen. Size bars represent 30 (A-B) and $100 \mu \mathrm{m}(\mathrm{C}-\mathrm{H})$. 
Table 2 Proliferation and hormone expression during early human pancreas development. For ratios of hormone-expressing cells, the prevalence of the least detected cell type was adjusted to $1 \cdot 0$ (note that PP was not detected at 8 w.p.c.). Two dorsal pancreata were examined at each stage and multiple sections analysed for each hormone

Ratio of hormone-expressing cells

\begin{tabular}{|c|c|c|c|c|}
\hline & Insulin & Glucagon & Somatostatin & PP \\
\hline 8 w.p.c. & $51 \cdot 4$ & $4 \cdot 0$ & $1 \cdot 0$ & - \\
\hline 10 w.p.c. & $38 \cdot 8$ & $4 \cdot 8$ & $5 \cdot 5$ & $1 \cdot 0$ \\
\hline
\end{tabular}

to $10-12$ cells in diameter, remained more prevalent than those for glucagon or other hormones. Colocalisation has been described previously during the first trimester of human development in $>90 \%$ of hormone-positive cells (Polak et al. 2000). In our experiments, controlled by using more than one primary antibody to the different hormones, only a small proportion of isolated cells prior to islet formation co-expressed both insulin/glucagon and insulin/somatostatin (data not shown). For glucagon- and somatostatin-positive cells, $<10 \%$ also expressed insulin (corresponding values for insulin-positive cells are much lower given their greater prevalence). At 12 w.p.c., the insulin-positive clusters were $\sim 20$ cells in maximum diameter with some of these aggregations containing other cells independently expressing the other islet hormones (Fig. 2C). One week later, endocrine cells had aggregated into larger primitive islet structures expressing all four hormones (Fig. 2D). Islet size was increased in the pancreatic body at later time-points during the second and third trimester (Fig. 2E-G).

\section{Expression of maturity markers in human fetal islets}

Although independent insulin expression is suggestive, by itself it is limited as a marker of 'true' fetal beta cell differentiation. To address this, we studied for the first time the expression of additional markers characteristic of more mature beta cell function. PC1/3, which cleaves proinsulin, and islet amyloid polypeptide (IAPP), cosecreted with insulin in mature beta cells, were detected centrally in islets at 12 and 14 w.p.c. (Fig. 3A, B, E, F). By dual immunofluorescence PC1/3 - expressed in all insulin-positive cells (Fig. 3M) - was also detected less strongly in somatostatin-positive cells (Fig. 3U corresponding to the asterisked regions in Fig. $3 \mathrm{~A}$ and E). IAPP was detected in nearly all insulin- and glucagon-positive cells but not somatostatin-positive cells (Fig. 3N, R and V). Colocalisation studies were not informative with PP, as islets at this stage of human development barely expressed this hormone. At term, PC1/3 and IAPP almost exclusively localised to beta cells (Fig. 3I, J, data not shown). In contrast, at 12 and 14 w.p.c., the glucose transporter, GLUT2 and the secretory marker, Chromogranin A were most strongly expressed in the periphery of fetal pancreatic islets (Fig. 3C, D, G, H) colocalising with glucagon (Fig. 3S, T). Much lower level central detection of both markers (arrowheads in Fig. 3C and D) corresponded to weaker colocalisation with insulin (faintly visible as orange-yellow by dual immunofluorescence in Fig. 3P). This expression profile persisted in pancreas sections at term (Fig. 3K, L).

Vascular development during human pancreas development and endocrine differentiation

Although expression data suggested relatively mature fetal beta cells by the end of the first trimester, their function as endocrine cells depends on coordinated vascular development. We studied this by the expression of the vascular endothelial cell marker, CD34. At CS17/41 d.p.c., the peri-pancreatic mesenchyme contained strands of cells positive for CD34 (Fig. 4A). Similarly, at 8.5 w.p.c., the scattered insulin-positive cells were not in particularly close association with CD34-positive vascular endothelial cells (Fig. 4B, C). In contrast, by 10 w.p.c. and later time-points, all observed aggregations of insulin-positive cells greater than five cells in diameter were in contact with multiple CD34-positive structures (Fig. 4D-F). These developing vessels penetrated the fetal islets at 14 w.p.c. (Fig. 4G).

\section{Transition from epithelial progenitor cell to fetal beta cell}

Given the discrepancy between our data, using multiple primary antibodies, and the extensive hormone colocalisation observed by Polak and colleagues (Polak et al. 2000), we sought to investigate more closely the transition from

Table 3 Proliferation and hormone expression during early human pancreas development: percentage of total pancreatic epithelial cells positive for Ki67 or insulin

\begin{tabular}{|c|c|c|c|}
\hline & CS17/41 d.p.c. & 8 w.p.c. & 10 w.p.c. \\
\hline Ki67+ cells $(\%)$ & $48 \cdot 9 \pm 4 \cdot 3$ & $12 \cdot 4 \pm 1 \cdot 9$ & $8 \cdot 4 \pm 0 \cdot 8$ \\
\hline Insulin + cells (\%) & ND & $0 \cdot 9 \pm 0 \cdot 3$ & $10 \cdot 4 \pm 2 \cdot 5$ \\
\hline$\%$ Insulin + cells also Ki67+ & Insulin ND & $4 \cdot 3$ & $0 \cdot 7$ \\
\hline
\end{tabular}

ND, not detected. 


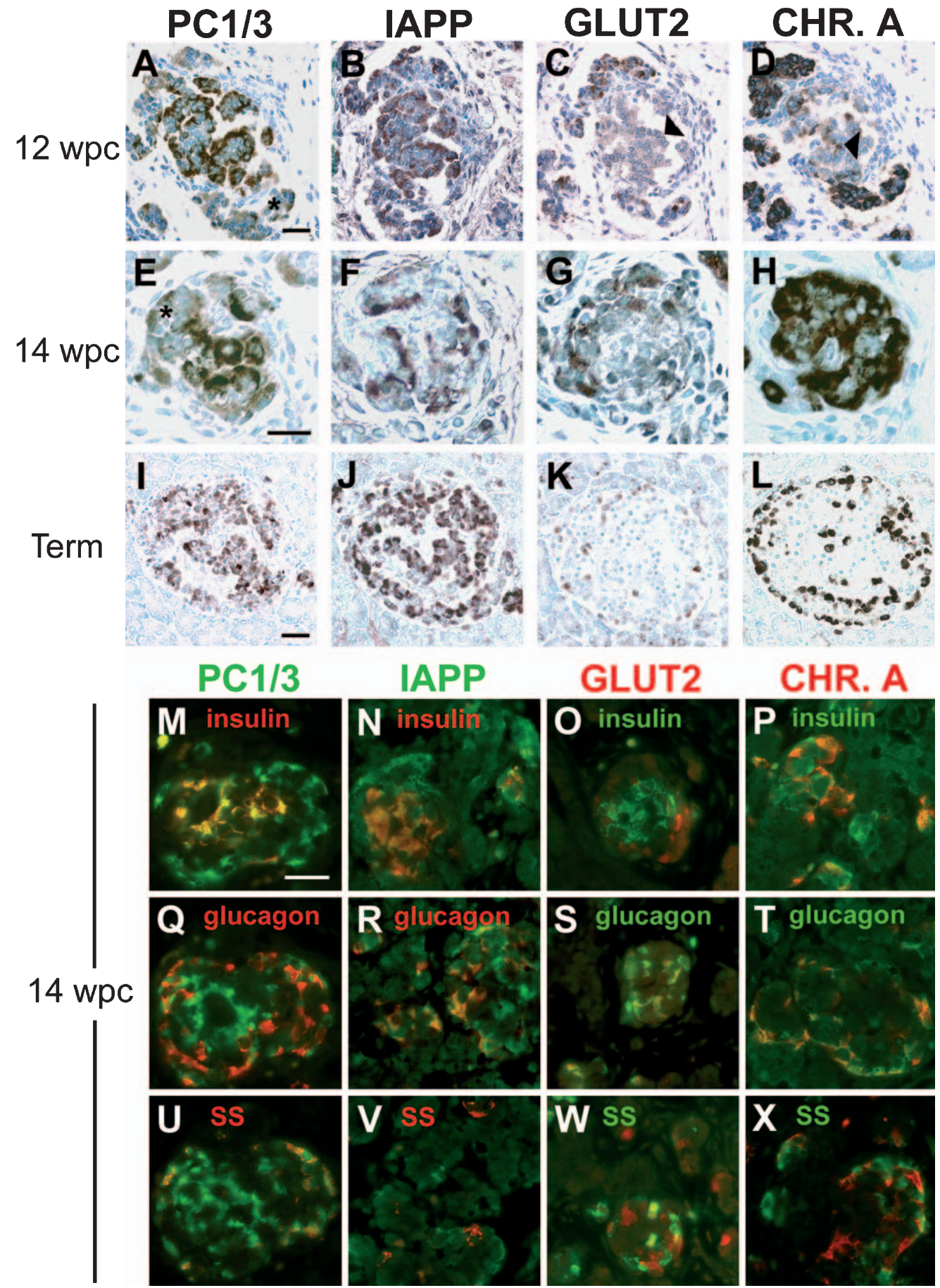

Figure 3 Expression of PC1/3, IAPP, GLUT2 and Chromogranin A in the human fetal pancreas. Transverse sections of human dorsal pancreas at 12 and 14 w.p.c. and term. (A)-(L) For each horizontal panel of serial sections (age on the left), PC1/3, IAPP, GLUT2 and Chromogranin A (CHR. A) bright-field immunohistochemistry is shown vertically, counter-stained with toluidine blue. Asterisks and arrowheads mark regions of weaker detection. (M)-(X). Dual immunofluorescence at 14 w.p.c. Red (Texas Red) or green (FITC) staining indicates single detection of the corresponding protein; orange-yellow marks colocalisation. Size bars for $\mathrm{A}-\mathrm{D}, \mathrm{E}-\mathrm{H}, \mathrm{I}-\mathrm{L}$ and $\mathrm{M}-\mathrm{X}$ represent $100 \mu \mathrm{m}$. SS, somatostatin. 

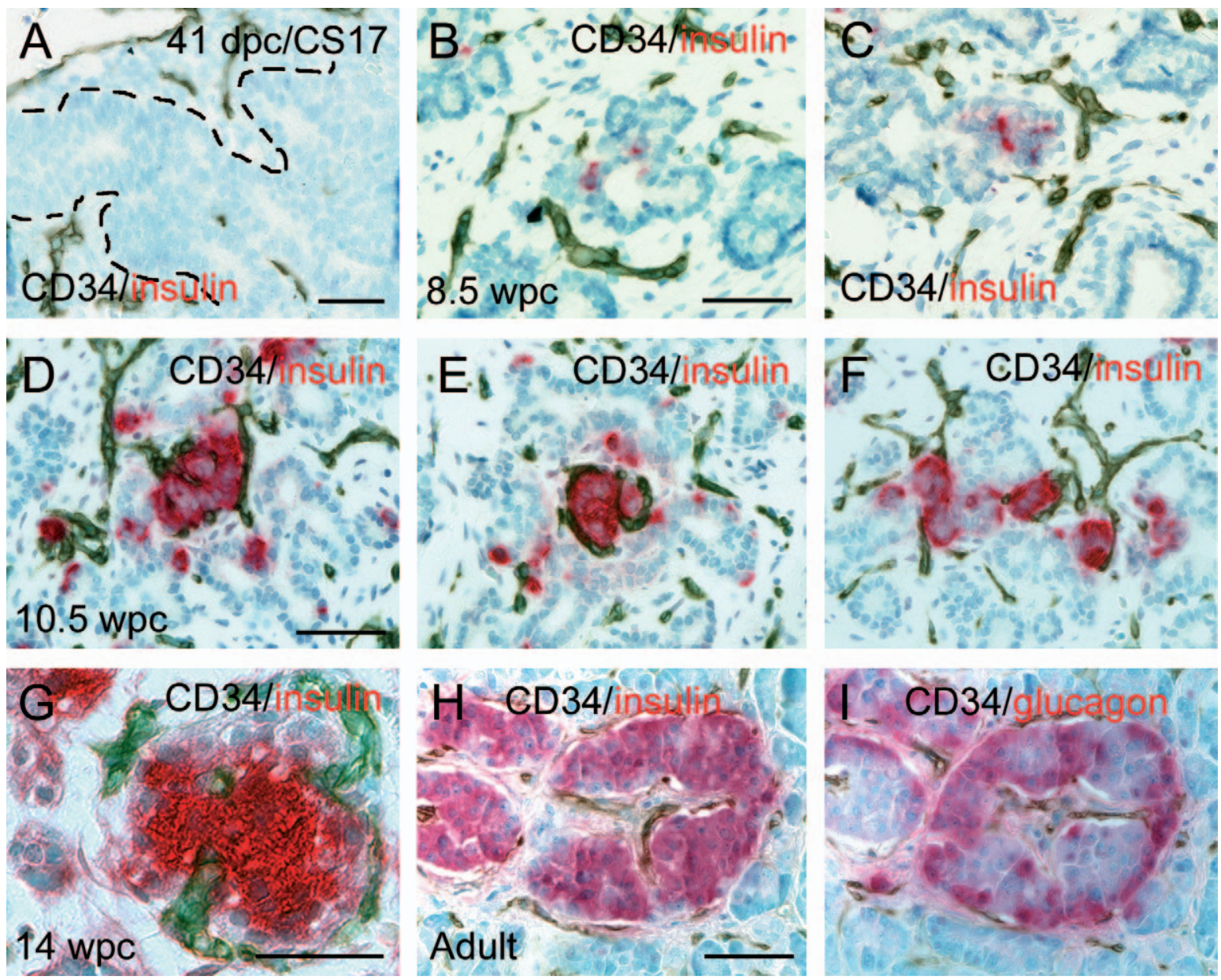

Figure 4 CD34-positive cells demarcate vascular development in the developing human pancreas. Bright-field dual immunohistochemistry (CD34, brown; insulin or glucagon, red) of transverse sections of developing human pancreas counter-stained with toluidine blue. (A) $4 \mathrm{Idpc} / \mathrm{CS} 17$ (B), (C) Two examples at 8.5 w.p.c. (D)-(F) Three examples at 10.5 w.p.c. (G) 14 w.p.c. (H), (I) Adult. Size bars represent $200 \mu \mathrm{m}$.

pancreatic epithelial cell to fetal beta cell. Cytokeratin 19 (CK19) is widely expressed within the ventral half of the early human embryo including the pancreatic epithelial cells (Fig. 5A, B). Although a ductal cell marker in adult tissue (Fig. 5I, J), within the early fetal pancreas, CK19 demarcates all of the pancreatic epithelial cells (Fig. 5C), a small proportion of which co-express insulin. However, similar to our data on SOX9 expression during human beta cell differentiation (Piper et al. 2002), the detection of CK19 is sequentially diminished in insulin-positive cells, as the primitive islet structures become distinct from the CK19-positive branched epithelia (Fig. 5C-H).

Approximately half the embryonic pancreatic epithelial cells at 41 d.p.c./CS17 expressed Ki67, a marker of cellular proliferation (Fig. 6A; Table 3). This value dropped during early fetal pancreas development with most proliferating cells being located peripherally as endocrine differentiation proceeded centrally (Fig. 6C, D). Ki67 immunoreactivity was only detected in very few insulin-positive cells during the first trimester (Table 3).

PDX1 expression during human pancreas development and endocrine differentiation

Finally, given its association with pancreatic agenesis and MODY4, we determined the expression profile of PDX1. At 26 d.p.c./CS12, PDX1 was detected in cell nuclei at the inception of pancreatic bud outgrowth from the duodenum (Fig. 7A). This expression was much more robustly detected in all pancreatic epithelial cells at 41 d.p.c./CS17 and during the early fetal period (Fig. 7B-D). Following islet formation at $12-13$ w.p.c., PDX1 remained in the nuclei of non-endocrine epithelial 

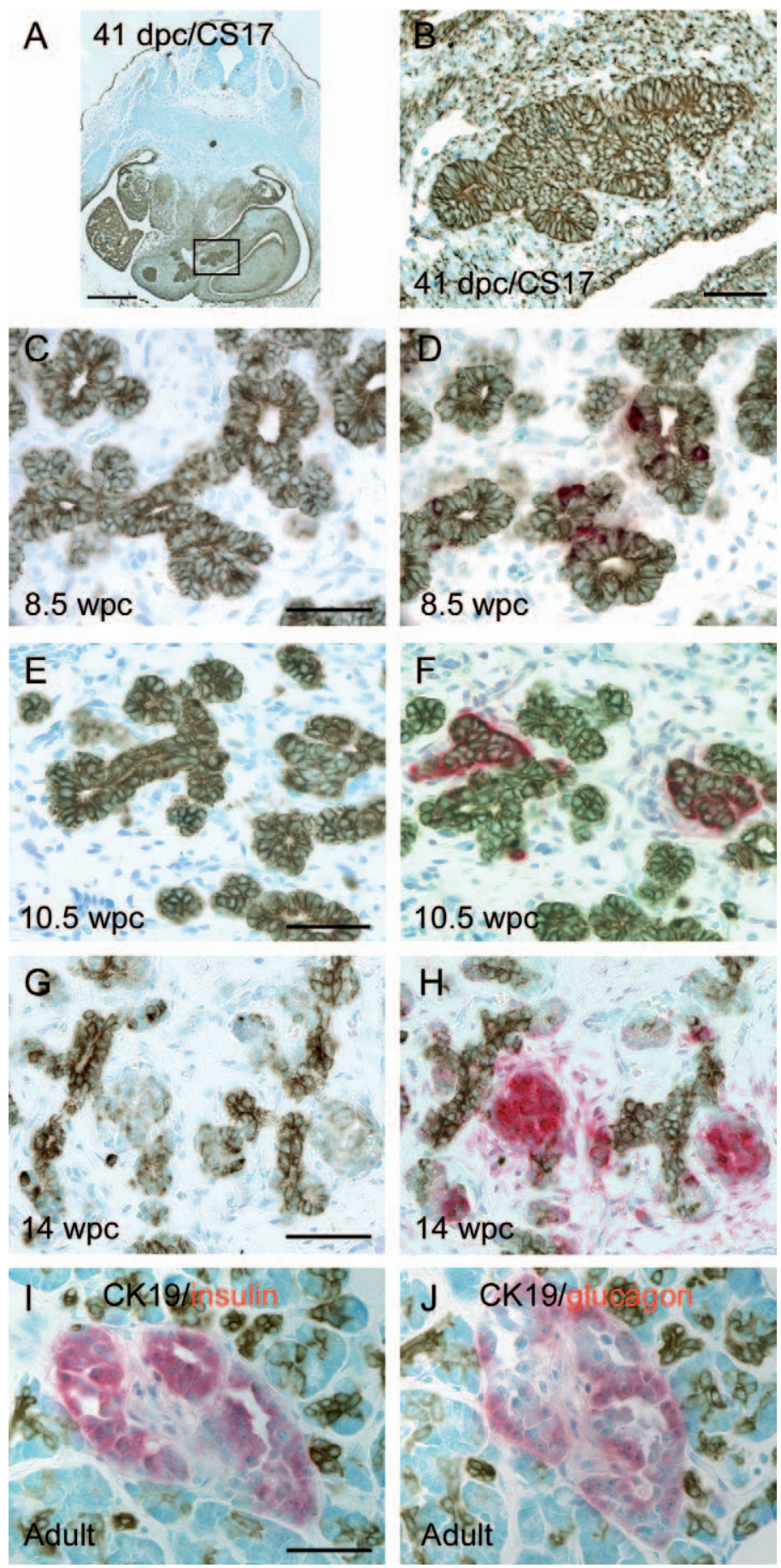

Figure 5 CK19 expression diminishes with differentiation of insulin-positive fetal beta cells. (A) CK19 immunoreactivity (brown) in transverse section of human embryo at 41 d.p.c. counter-stained with toluidine blue. Boxed pancreatic region at higher magnification in $(B) .(C)-(H)$ Left panels $(C, E$ and G) show brown CK19 staining alone. Corresponding right panels (D, F and $\mathrm{H})$ show adjacent tissue section (at $5 \mu \mathrm{m}$ ) stained for both CK19 (brown) and insulin (red). The expression of CK19 in insulin-positive cells is progressively weaker at 10.5 and 14 w.p.c. (I), (J) Adult pancreas stained brown for CK19 and in red for insulin (I) or glucagon (J). Size bars represent $200 \mu \mathrm{m}$. 

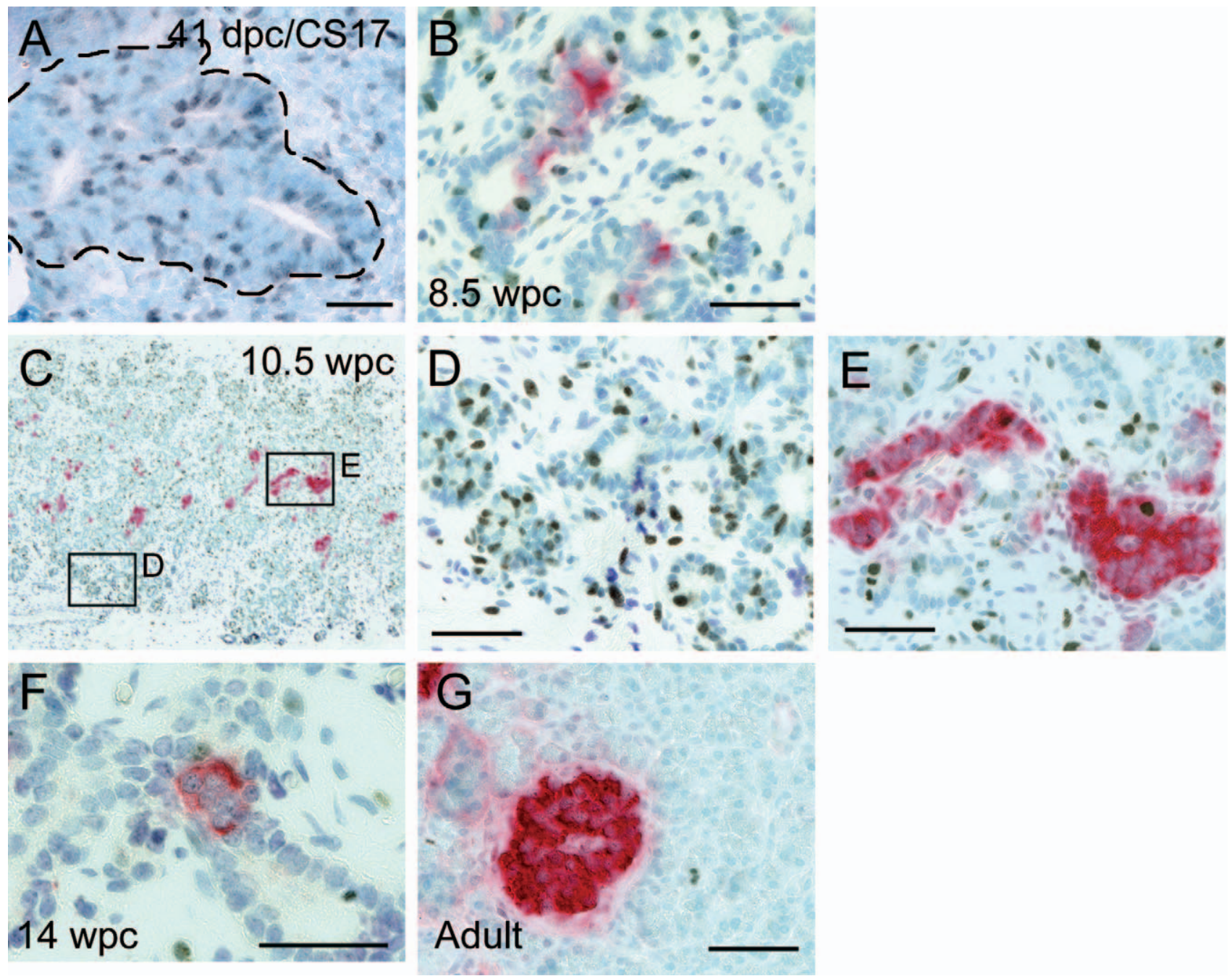

Figure 6 Ki67 immunoreactivity during human embryonic and early fetal pancreas development. Bright-field dual immunohistochemistry for Ki67 (brown) and insulin (red) on transverse sections of developing human pancreas counter-stained with toluidine blue. (A) Boundary of pancreatic epithelial structures highlighted by broken line. (C) Peripheral and central boxed regions shown at higher magnification in (D) and (E) respectively. Size bars represent $200 \mu \mathrm{m}$.

cells. However, within the same tissue section, a more diffuse pattern of staining was observed in islet cells, consisting of both cytoplasmic and nuclear detection (Fig. 7E, F). By dual immunofluorescence at 14 w.p.c., this expression colocalised strongly with insulin (Fig. 7G). As control, murine pancreas was included (Fig. 7L-N). Processed in parallel and exposed to an identical dilution of antibody, it revealed the strongest $\mathrm{Pdx} 1$ expression in the nuclei of mouse fetal beta cells (Fig. $7 \mathrm{~N}$ ). Later during human fetal development and in adult pancreatic sections, PDX1 expression remained in duct cells, however was most strongly detected in islets, in keeping with its established role in glucose-regulated insulin production (Fig. 7J, K).

\section{Discussion}

This immunohistochemical study describes the development of endocrine cells within the human embryonic and early fetal pancreas. The findings are related to the first description of vascular development and the expression of PDX1 and several markers of differentiated islet cell function. It concurs with previous morphological descriptions of the human pancreas from the second trimester onwards (Lukinius et al. 1992, Bouwens et al. 1997). This includes the onset of islet formation at 12-13 w.p.c. (Falin 1967) and the distinct hormone profile in the ventral pancreatic derivative, where sparse alpha cells are replaced by more abundant PP cells (Fiocca et al. 1983). Previously, 

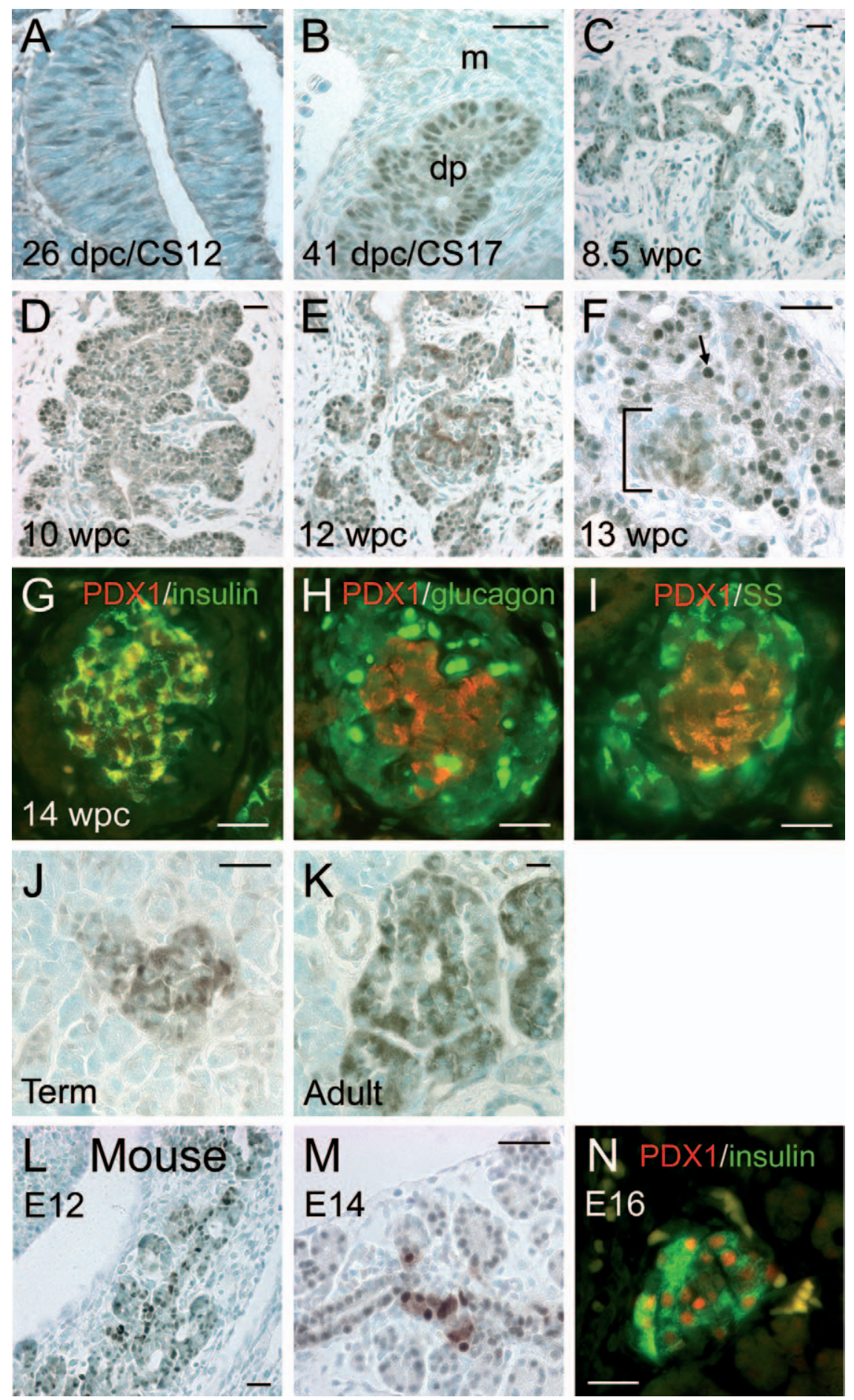

Figure 7 Expression of PDX1 within the human embryonic and fetal pancreas. Bright-field images counter-stained with toluidine blue $(A-F, J-M)$ and dual immunofluorescence $(G-I, N)$ of transverse sections of embryonic, fetal and adult pancreas. (A)-(K) Human. (L)-(N) Mouse. (F) Nuclear epithelial staining (arrow) lies within $100 \mu \mathrm{m}$ of the more diffuse nuclear/ cytoplasmic staining of islet cells (open box). $m$, mesenchyme; $d p$, dorsal pancreas. Size bars represent $100 \mu \mathrm{m}$. 
several studies have examined the human endocrine pancreas during the first trimester. Although discordant with some (Like \& Orci 1972, Bocian-Sobkowska et al. 1997) (potentially due to methodology in Like \& Orci's study, which relied upon non-immunohistochemical techniques), we concur with others that both insulin and glucagon can be detected by 8 weeks of development (Clark \& Grant 1983, Stefan et al. 1983), including the slightly delayed detection of PP (Polak et al. 2000). We further agree with those making the distinction that insulin-positive cells are the more prevalent cell type in humans during early fetal development (Clark \& Grant 1983, Stefan et al. 1983). These latter studies also support our relatively sparse colocalisation of insulin and glucagon $(<10 \%$; as in a previous study upon mid-gestational specimens (De Krijger et al. 1992)) compared with the study by Polak and colleagues (>90\%) (Polak et al. 2000). Although the reasons for this discrepancy are unclear, insulin-positive cells being the most prevalent endocrine cells (this study; Clark \& Grant 1983, Stefan et al. 1983) restricts the number of cells in which it is possible for the hormone to colocalise with glucagon. Data from transgenic mice also demonstrate that true alpha and beta cells have never co-expressed the hormonal marker of the other cell type (Herrera 2000). Taken together, the relative lack of colocalisation, the sequential increase and clustering of insulin-positive cells into vascularised ordered islets at 12-13 w.p.c., and the expression of multiple markers of maturity, strongly imply that these cells are true fetal beta cells. Our data are also concordant with fetal beta cells arising centrally by differentiation from CK19-positive precursors rather than by proliferation of pre-existing hormone-positive cells both during the first trimester (Polak et al. 2000) and during later human fetal development (Bouwens et al. 1997). Within this model, after the embryonic period, most Ki67 immunoreactivity resides closer to the peripheral mesenchyme (this study; Polak et al. 2000), consistent with data from rodents indicating anti-endocrine, pro-proliferative roles for peri-pancreatic mesenchyme (Golosow \& Grobstein 1962, Miralles et al. 1998).

Enormous insight has been gained into mammalian pancreas formation from other species. The murine pancreas starts to develop as ventral and dorsal outgrowths of foregut endoderm from embryonic day (E) 9.5 (Slack 1995, Kim \& Hebrok 2001). Hormone expression commences early at E9.5-10 with glucagon preceding insulin (Teitelman et al. 1993). Somatostatin and PP mRNA are also detected at this time (Herrera et al. 1991, Gittes \& Rutter 1992). However, the proteins only appear from E15.5 and E16 respectively (Teitelman et al. 1993, Jackerott et al. 1996). In mice, islets are formed properly only within a few days of birth after a secondary wave of beta cell differentiation (Slack 1995). These data present several differences between pancreas development in mice and humans. Firstly, the progression from foregut endoderm to insulin-synthesising cell is very rapid in the mouse (E9.5 to $\sim$ E10). Although pancreatic differentiation from foregut endoderm was initiated at an equivalent time in human (26 d.p.c.), corresponding embryonic staging would predict significant insulin expression by $\sim 33$ d.p.c. (equivalent to E11). In contrast, our data show that insulin expression is only apparent more than 2 weeks later, closer to the end of the human embryonic period. The cause or functional consequence of this delayed hormone synthesis in the human species is unknown, however it supports the theory that embryological stages are not as closely conserved as previously thought (Richardson et al. 1997). Furthermore, our specific findings at CS21/52 d.p.c., defined by limb positioning, finger morphology and the superficial cranial vasculature (O’Rahilly \& Müller 1987, Bullen \& Wilson 1997), illustrate that insulin expression precedes that of glucagon in the human (also consistent with the subsequent preponderance of insulin-positive cells at 8 and 10 w.p.c.). These results were confirmed independently using different primary antibodies. All four islet cell hormones were detected by 10 w.p.c. ( $\sim 70$ d.p.c.) differing from mouse in the early detection of somatostatin and PP protein. Once islets have assembled at 12-13 w.p.c. in human (compared with near term in mice), the co-expression of PC1/3 and IAPP with insulin implies fetal beta cells may be capable of processing and secreting insulin. In contrast, the relatively sparse detection of GLUT2 in fetal beta cells aligns closely with the human adult beta cell, representing a species difference from rats (De Vos et al. 1995, Heimberg et al. 1995). IAPP also appeared present in both human (this study) and mouse fetal alpha cells (Wilson et al. 2002), in contrast to PC1/3, which was absent from human fetal alpha cells. Lack of this enzyme would prohibit the potential synthesis of the glucagon-like peptides, GLP-1 and GLP-2 that has been noted in mice fetal alpha cells (Wilson et al. 2002).

The only previous description of PDX1 in human tissues is in the adult pancreas, which also demonstrated more diffuse detection of PDX1 in islet beta cells (Heimberg et al. 2000). Our first description of PDX1 expression in the nuclei of human embryonic and early fetal pancreas cells strongly supports the transcription factor's proposed role in human pancreas formation (Stoffers et al. 1997b). The expression profile in human fetal beta cells also included detection within the cytoplasm, in contrast to the adjacent epithelial cells of the same tissue section (providing a valuable internal control). Cytoplasmic localisation of PDX1 has been described in insulinoma cell lines, depending upon phosphorylation status and extracellular glucose concentration (Macfarlane et al. 1999, Elrick \& Docherty 2001). Altered localisation would modify the influence of the transcription factor on gene expression.

In conclusion, these data support the function of vascularised human fetal beta cells as true endocrine cells 
by the end of the first trimester of human pregnancy, with PDX1 expression in agreement with its developmental mutation phenotype. The relative delay to hormone biosynthesis and preferential expression of insulin rather than glucagon also suggest subtle differences from the endocrine differentiation programme in mouse.

\section{Acknowledgements}

We acknowledge the use of material from the Newcastle Human Developmental Biology Resource and thank staff at the Princess Anne Hospital, Southampton, for assistance with collection of clinical specimens. We are grateful for support towards image publication costs from Carl Zeiss Ltd and the kind gift of anti-PDX1 from Dr Chris Wright, Vanderbilt University.

\section{Funding}

This work was funded by the Juvenile Diabetes Research Foundation. Neil Hanley is a Department of Health Clinician Scientist. No conflict of interest is relevant to this study.

\section{References}

Bocian-Sobkowska J, Zabel M, Wozniak W \& Surdyk-Zasada J 1997 Prenatal development of the human pancreatic islets. Immunocytochemical identification of insulin-, glucagon-, somatostatin- and pancreatic polypeptide-containing cells. Folia Histochemica et Cytobiologica 35 151-154.

Bouwens L, Lu WG \& De Krijger R 1997 Proliferation and differentiation in the human fetal endocrine pancreas. Diabetologia 40 398-404.

Bullen P \& Wilson DI 1997 The Carnegie staging of human embryos: a practical guide. In Molecular Genetics of Early Human Development, pp 27-50. Eds T Strachan, DI Wilson \& S Lindsay. Oxford: BIOS.

Clark A \& Grant AM 1983 Quantitative morphology of endocrine cells in human fetal pancreas. Diabetologia 25 31-35.

De Krijger RR, Aanstoot HJ, Kranenburg G, Reinhard M, Visser WJ \& Bruining GJ 1992 The midgestational human fetal pancreas contains cells coexpressing islet hormones. Developmental Biology 153 368-375

De Vos A, Heimberg H, Quartier E, Huypens P, Bouwens L, Pipeleers D \& Schuit F 1995 Human and rat beta cells differ in glucose transporter but not in glucokinase gene expression. Journal of Clinical Investigation 96 2489-2495.

Edlund H 2002 Pancreatic organogenesis - developmental mechanisms and implications for therapy. Nature Reviews Genetics 3 524-532.

Elrick LJ \& Docherty K 2001 Phosphorylation-dependent nucleocytoplasmic shuttling of pancreatic duodenal homeobox-1. Diabetes 50 2244-2252.

Falin LI 1967 The development and cytodifferentiation of the islets of Langerhans in human embryos and foetuses. Acta Anatomica $\mathbf{6 8}$ $147-168$.

Fiocca R, Sessa F, Tenti P, Usellini L, Capella C, O'Hare MM \& Solcia E 1983 Pancreatic polypeptide (PP) cells in the PP-rich lobe of the human pancreas are identified ultrastructurally and immunocytochemically as F cells. Histochemistry 77 511-523.
Fougerousse F, Bullen P, Herasse M, Lindsay S, Richard I, Wilson D, Suel L, Durand M, Robson S, Abitbol M, Beckmann JS \& Strachan T 2000 Human-mouse differences in the embryonic expression patterns of developmental control genes and disease genes. Human Molecular Genetics 9 165-173.

Gittes GK \& Rutter WJ 1992 Onset of cell-specific gene expression in the developing mouse pancreas. PNAS 89 1128-1132.

Golosow N \& Grobstein C 1962 Epitheliomesenchymal interaction in pancreatic morphogenesis. Development 4 242-255.

Hanley NA, Hagan DM, Clement-Jones M, Ball SG, Strachan T, Salas-Cortes L, McElreavey K, Lindsay S, Robson S, Bullen P, Ostrer H \& Wilson DI 2000 SRY, SOX9, and DAX1 expression patterns during human sex determination and gonadal development. Mechanisms of Development 91 403-407.

Heimberg H, De Vos A, Pipeleers D, Thorens B \& Schuit F 1995 Differences in glucose transporter gene expression between rat pancreatic alpha- and beta-cells are correlated to differences in glucose transport but not in glucose utilization. Journal of Biological Chemistry 270 8971-8975.

Heimberg H, Bouwens L, Heremans Y, Van De Casteele M, Lefebvre V \& Pipeleers D 2000 Adult human pancreatic duct and islet cells exhibit similarities in expression and differences in phosphorylation and complex formation of the homeodomain protein Ipf-1. Diabetes 49 571-579.

Herrera PL 2000 Adult insulin- and glucagon-producing cells differentiate from two independent cell lineages. Development 127 $2317-2322$.

Herrera PL, Huarte J, Sanvito F, Meda P, Orci L \& Vassalli JD 1991 Embryogenesis of the murine endocrine pancreas; early expression of pancreatic polypeptide gene. Development 113 1257-1265.

Jackerott M, Oster A \& Larsson LI 1996 PYY in developing murine islet cells: comparisons to development of islet hormones, NPY, and BrdU incorporation. Journal of Histochemistry and Cytochemistry $\mathbf{4 4}$ 809-817.

Jonsson J, Carlsson L, Edlund T \& Edlund H 1994 Insulin-promoterfactor 1 is required for pancreas development in mice. Nature 371 606-609.

Kim SK \& Hebrok M 2001 Intercellular signals regulating pancreas development and function. Genes and Development 15 111-127.

Like AA \& Orci L 1972 Embryogenesis of the human pancreatic islets: a light and electron microscopic study. Diabetes 21 511-534.

Lukinius A, Ericsson JL, Grimelius L \& Korsgren O 1992 Ultrastructural studies of the ontogeny of fetal human and porcine endocrine pancreas, with special reference to colocalization of the four major islet hormones. Developmental Biology 153 376-385.

Macfarlane WM, McKinnon CM, Felton-Edkins ZA, Cragg H, James RF \& Docherty K 1999 Glucose stimulates translocation of the homeodomain transcription factor PDX1 from the cytoplasm to the nucleus in pancreatic beta-cells. Journal of Biological Chemistry 274 1011-1016.

Miralles F, Czernichow P \& Scharfmann R 1998 Follistatin regulates the relative proportions of endocrine versus exocrine tissue during pancreatic development. Development 125 1017-1024.

Offield MF, Jetton TL, Labosky PA, Ray M, Stein RW, Magnuson MA, Hogan BL \& Wright CV 1996 PDX-1 is required for pancreatic outgrowth and differentiation of the rostral duodenum. Development 122 983-995.

O'Rahilly R \& Müller F 1987 Developmental Stages in Human Embryos, vol. publ. no. 637. Meriden: Meriden-Stinehour Press, Carnegie Institution of Washington.

Peshavaria M, Gamer L, Henderson E, Teitelman G, Wright CV \& Stein R 1994 XIHbox 8, an endoderm-specific Xenopus homeodomain protein, is closely related to a mammalian insulin gene transcription factor. Molecular Endocrinology 8 806-816.

Piper K, Ball SG, Keeling JW, Mansoor S, Wilson DI \& Hanley NA 2002 Novel SOX9 expression during human pancreas development correlates to abnormalities in Campomelic dysplasia. Mechanisms of Development 116 223-226. 
Polak M, Bouchareb-Banaei L, Scharfmann R \& Czernichow P 2000 Early pattern of differentiation in the human pancreas. Diabetes 49 225-232.

Richardson MK, Hanken J, Gooneratne ML, Pieau C, Raynaud A, Selwood L \& Wright GM 1997 There is no highly conserved embryonic stage in the vertebrates: implications for current theories of evolution and development. Anatomy and Embryology 196 91-106.

Sander M \& German MS 1997 The beta cell transcription factors and development of the pancreas. Journal of Molecular Medicine $\mathbf{7 5}$ $327-340$

Slack JM 1995 Developmental biology of the pancreas. Development 121 1569-1580.

Stefan Y, Grasso S, Perrelet A \& Orci L 1983 A quantitative immunofluorescent study of the endocrine cell populations in the developing human pancreas. Diabetes 32 293-301.

Stoffers DA, Ferrer J, Clarke WL \& Habener JF 1997a Early-onset type-II diabetes mellitus (MODY4) linked to IPF1. Nature Genetics 17 138-139.
Stoffers DA, Zinkin NT, Stanojevic V, Clarke WL \& Habener JF $1997 b$ Pancreatic agenesis attributable to a single nucleotide deletion in the human IPF1 gene coding sequence. Nature Genetics 15 106-110.

Teitelman G, Alpert S, Polak JM, Martinez A \& Hanahan D 1993 Precursor cells of mouse endocrine pancreas coexpress insulin, glucagon and the neuronal proteins tyrosine hydroxylase and neuropeptide Y, but not pancreatic polypeptide. Development 118 1031-1039.

Wilson ME, Kalamaras JA \& German MS 2002 Expression pattern of IAPP and prohormone convertase $1 / 3$ reveals a distinctive set of endocrine cells in the embryonic pancreas. Mechanisms of Development 115 171-176.

Received 29 September 2003

Accepted 18 December 2003 